\title{
El lugar de los trabajadores portuarios en la historia laboral (Argentina, 1880-1930)*
}

\author{
The place of port workers in labor history \\ (Argentina, 1880-1930)
}

Natalia Paula Fanduzzi Ciancaglini**

\section{RESUMEN}

Este artículo indaga sobre los trabajadores portuarios en la Argentina en el período 18801930 en la producción historiográfica. Su objetivo es delinear un estado de la cuestión que sintetice la información dispersa, evidenciando lo que se ha escrito y su tratamiento según los distintos contextos de producción vigentes. La importancia de los portuarios en la conformación del movimiento obrero argentino es ampliamente reconocida; sin embargo, hasta la actualidad no se ha sistematizado su conocimiento en el ámbito nacional desde la perspectiva de la historia de los trabajadores. En este sentido, proponemos una agenda preliminar de trabajo para futuras investigaciones.

PALAVRAS-CHAVE: Mundo del trabajo portuario. Argentina agro-exportadora. Historiografía de los trabajadores.

\section{ABSTRACT}

This paper examines the dock workers in Argentina in the period of 1880-1930 in the historiographical production. It aims to outline a state of affairs that synthesizes information scattered, showing what has been written and its treatment according to different contexts of current production. The importance of the port in shaping the Argentine labor movement is widely recognized, but until now, the knowledge about it has not been systematized at the national level from the perspective of the history of workers. In this regard, we propose a preliminary agenda for future research.

KEY-WORDS: Dock work world. Argentina agro-export. Workers historiography.

Existe un amplio consenso en el campo de la historia laboral en la Argentina sobre la importancia de los trabajadores portuarios en la conformación del movimiento obrero nacional. Es posible hallar análisis generales y algunas descripciones minuciosas de hechos ocurridos en los puertos, en prácticamente todas las obras que hacen alusión a la configuración de la Argentina moderna hacia fines del siglo XIX y principios del XX, desde los primeros escritos contemporáneos a los hechos

\footnotetext{
* El presente artículo se ha realizado con el apoyo financiero del CONICET a través de una Beca Doctoral Tipo I. El mismo forma parte de mi tesis doctoral en elaboración sobre 'Puerto y trabajadores en el Sudoeste de Buenos Aires, Argentina. Clase obrera, capital y trabajo en una modernización descentrada (1884-1930)', por lo que deseo agradecer especialmente los valiosos comentarios realizados por mi directora la Dra. Mirta Zaida Lobato durante su preparación.

**Universidad Nacional del Sur. Dirección de correo electrónico. nfanduzzi@gmail.com
} 
hasta la actualidad. Inmersos en esta búsqueda hallamos una gran cantidad de datos dispersos sobre la manifestación de distintos conflictos de clase, especialmente sobre huelgas iniciadas y/ o apoyadas por los trabajadores portuarios que son analizadas en el marco de la organización del movimiento obrero nacional. En segundo lugar, el tema aparece vinculado con la definición del trabajo urbano en la etapa de modernización. También encontramos en la bibliografía referencias a posibles modelos de abordaje y a problemas de investigación no desarrollados todavía, insertos en el contexto de escritura de la historia de los sectores populares y del proceso de proletarización de la clase obrera. Sin embargo, salvo la tesis doctoral de Geoffroy de Laforcade (2001) sobre los trabajadores del puerto de Buenos Aires, no hemos hallado otros estudios acabados que aborden el tema de manera exclusiva y sistemática desde la perspectiva de la historia social del trabajo. En este punto, deseamos destacar no obstante, el trabajo desarrollado por el colectivo de trabajo que conforma el Grupo de Estudios Sociales Marítimos (GESMar) con sede en la Universidad Nacional de Mar del Plata, Argentina; en cuyo seno se están desarrollando actualmente distintas tesis doctorales sobre temas vinculados con áreas portuarias, se ha iniciado la publicación de una revista sobre esta temática ${ }^{2}$ y se han organizando las primeras J ornadas Interdisciplinarias de Estudios Portuarios en noviembre de 2009.

Esta situación de reconocimiento de la importancia de la temática por un lado, y de carencia de obras publicadas que la aborden dentro del campo historiográfico profesional por otro; antes de ser aceptada como un a priori que justificaría por sí mismo la necesidad de profundizar el estudio de los trabajadores portuarios, nos sugiere la necesidad de realizar un balance que inserte el tema dentro de la producción historiográfica sobre los trabajadores en la Argentina. Nuestro objetivo no es presentar un inventario exhaustivo de todo lo que se ha escrito sobre los portuarios en el pasado, sino organizar preliminarmente los enfoques disponibles en la literatura atendiendo a las preguntas que guiaron la investigación de la temática en el pasado, con la finalidad de poder contextualizarla dentro de las distintas tradiciones historiográficas y sus respectivos contextos de producción, y a partir de allí delinear una agenda que considere críticamente los cambios producidos en la historia social del trabajo hasta la actualidad.

\footnotetext{
${ }^{2}$ La versión digital de la publicación Revista de Estudios Marítimos y Sociales puede consultarse en http:// estudiosmaritimos.wordpress.com.
} 


\section{I.}

En el contexto agro-exportador argentino de comienzos del siglo XX, el trabajo irrumpió como un problema central de la sociedad moderna. En este período los/as trabajadores/as protagonizaron un proceso de lucha por la obtención de derechos sociales y políticos, vinculándose dialécticamente con las modificaciones registradas en la sociedad global y desplegando un amplio repertorio de protesta y confrontación. Repertorio que puso de manifiesto el pasaje de la percepción individual del asalariado al surgimiento de la acción colectiva organizada, plasmada en petitorios, huelgas y otras formas de resistencia. Estos conflictos en el mundo del trabajo; se expresaron también en el aumento de la pobreza, las enfermedades y el hacinamiento habitacional, especialmente en los centros urbanos con mayor crecimiento poblacional originado en la afluencia masiva de inmigrantes fomentada por el Estado.

El afianzamiento del modelo agro-exportador determinó a su vez una articulación particular de las áreas portuarias con los ámbitos local, nacional e internacional en el marco de los profundos cambios de la época. Transformaciones que respondieron al despliegue de un proceso modernizador, surgido de las relaciones emanadas del pacto Neo-Colonial asociado con la consolidación de un capitalismo periférico en la región que ubicó al país en el concierto internacional como productor de materias primas suplementario de las potencias centrales. En este contexto, el capital creó una lógica y una dinámica de dominio particular vinculada con el comercio internacional y exhibió a nivel local conductas de apropiación y control de las finanzas, las salidas marítimas, las casas exportadoras y el transporte de hinterland, entre otras. En este sentido, en los puertos, la conexión de las economías regionales, nacional e internacional posibilitó la articulación de una compleja logística política y empresarial en la que intervinieron múltiples actores del sector público y privado en el manejo y circulación de grandes flujos materiales (mercaderías) e inmateriales (información) en el marco de relaciones sociales eminentemente urbanas (SILVA, 2003, p. 24-25).

Esta situación se manifestó en el crecimiento exponencial de las ciudades portuarias del litoral pampeano, no sólo Buenos Aires, sino también Rosario y Bahía Blanca entre otras asistieron a la concreción de profundos cambios (FALCON, 1984, p. 65). En estas ciudades se produjo un rápido crecimiento demográfico en paralelo con un acelerado proceso de urbanización, que incluyó la realización de las grandes obras de remodelación y de construcción portuaria. Cabe señalar, que desde el punto de vista del trabajo urbano, dichas obras de construcción de ferrocarriles, puertos y transportes, constituyeron la excepción a la regla, ya que hasta 1880 el trabajo en las ciudades se realizaba mayormente en pequeños talleres y bajo un 
régimen de explotación familiar (FALCON, 1986, p. 62). En los años siguientes, entre 1890 y 1914 aproximadamente, los sectores de actividad económica que emplearon mayor cantidad de mano de obra fueron el agropecuario y el urbano, incluyendo en este último a la industria, los trabajadores a domicilio, el comercio, la construcción, los portuarios y el transporte. Puntualmente en Buenos Aires, Rosario y Bahía Blanca, se agruparon los aproximadamente 20.000 obreros portuarios existentes en el país a principios del siglo XX (FALCON, 1986, p. 13).

En términos generales, podemos afirmar que el trabajo en los puertos argentinos en la época considerada era técnicamente primitivo y su estructura laboral se hallaba determinada por la contratación eventual y por la existencia de una abundante mano de obra de reserva que impactaba sobre las escalas salariales e influía negativamente sobre todo, en la situación de las categorías profesionales inferiores; situación constatable también en ciertos puertos europeos en el mismo período (HOBSBAWM, 1979, p. 222).

Los trabajadores portuarios, por su parte, constituyeron un gremio líder dentro del movimiento obrero argentino debido a su posición estratégica dentro del modelo económico nacional. A modo de ejemplo vale recordar que, en la Argentina a principios de siglo XX, el gremio de estibadores contaba con 15.000 obreros sindicalizados, uno de los mayores números registrados según fuentes sindicales; comprendiendo en la definición de organizados a aquellos miembros adheridos formalmente, que participaban en las actividades gremiales. Este número resulta útil como indicador general de la influencia que dicha sociedad de resistencia tenía sobre los trabajadores del sector (FALCON, 1986, p. 87-88), si bien en situaciones de conflicto en las zonas portuarias también participaban trabajadores no sindicalizados 3 .

En síntesis, la centralidad del trabajo en la etapa de auge agroexportador a principios del siglo XX se evidenció en la conflictiva redefinición del campo laboral, contenedora de un proceso de formación y consolidación de los sindicatos y de plasmación de los modos socialmente aceptables de violencia material y simbólica por parte de todos los agentes involucrados. Todo esto inserto en un contexto de modernización descentrada asociado con la implantación de un capitalismo periférico en el país que impactó de manera particular en las áreas portuarias. Los nodos exportadores/importadores durante el período experimentaron un inédito aumento poblacional como consecuencia de la inmigración masiva, así como un fuerte

\footnotetext{
3 Sobre las repercusiones del accionar del gremio de portuarios, podemos citar la huelga de estibadores de 1902, declarada inicialmente como sectorial y que derivó en general, afectando a los principales puertos del país y provocando la promulgación de la Ley Nacional de Residencia. (PRIETO, 2001, p. 137).
} 
cambio urbanístico. Estos cambios aparecieron reflejados en la prensa contemporánea como materializaciones del progreso indefinido impactando de modo particular en el mundo del trabajo portuario y afectando las experiencias de los trabajadores en los lugares de trabajo, los vínculos que desarrollaron entre sí y las relaciones que establecieron con los restantes agentes involucrados.

\section{II.}

Hasta aquí hemos presentado muy sintéticamente la centralidad del tema de los trabajadores portuarios en relación con los cambios sociales y económicos acaecidos en un contexto específico de modernización periférica. A continuación intentaremos identificar ¿cómo ha sido tratado el tema en la historiografía sobre los trabajadores? ¿cuáles son los focos de interés en la literatura existente? y ¿de qué modo se articulan estos interrogantes con un contexto de producción historiográfica que los excede? En primer lugar, vale recordar que el período temporal seleccionado, fines del siglo XIX y comienzos del XX, constituye un balizamiento temporal clásico dentro de la historia del movimiento obrero ${ }^{4}$, no sólo argentino, sino también latinoamericano, cuya utilidad entendemos que debería ser repensada en el marco de investigaciones específicas antes de aceptarse de modo acrítico como periodización auto-explicativa.

Tradicionalmente la investigación sobre los trabajadores en la Argentina se ha centrado en dos grandes problemas, la conformación del movimiento obrero a principios del siglo XX, durante la denominada fase gestacional de la lucha política organizada; y el peronismo focalizándose especialmente en la vinculación existente entre los sindicatos y el sistema político. Estos dos ejes temáticos han sido abordados en distintos momentos, desde diferentes enfoques disciplinares, constituyendo el corpus central de la producción historiográfica sobre los problemas referidos al mundo del trabajo (GUTIÉRREZ; ROMERO, 1995, p. 195-212). Teniendo esto presente, intentaremos introducir algunos de los enfoques desplegados en el estudio del mundo del trabajo en los puertos durante el período de auge agroexportador.

\footnotetext{
${ }^{4}$ Sobre la unidad analítica del período Gutiérrez y Lobato (1992, p. 36) sostienen que '[...] durante las dos primeras décadas del siglo XX, y en particular en la primera los combates por la obtención de las demandas, por el reconocimiento de las organizaciones gremiales o para paliar el sufrimiento de las clases desposeídas y la represión de la militancia fue conformando un cuadro de prácticas y representaciones que se distinguirá de aquel acuñado en las décadas posteriores. Este período fue el de la conformación de una identidad, el de la construcción de un marco de identificaciones, de un conjunto de símbolos que serán modificados en las décadas posteriores. El carácter proletario, internacionalista y radical se irá licuando y adquiriendo nuevos contenidos en las etapas siguientes $[\ldots]^{\prime}$
} 
Los primeros registros historiográficos en los que hallamos referencias a los trabajadores portuarios son las investigaciones realizadas por los denominados militantes historiadores, grupo formado por dirigentes políticos y gremiales cuyas obras -elaboradas con anterioridad a 1955- se apoyaron en las diputas ideológicas puestas de manifiesto en periódicos obreros, congresos y declaraciones de las distintas organizaciones (GUTIÉRREZ; LOBATO, 1992, p. 27). Esta producción se inserta dentro se una estructura de pensamiento que toma como sujeto central de sus investigaciones al proletariado industrial y al conflicto de clase, especialmente las huelgas, como eje articulador de sus explicaciones. Los militantes obreros se enfocaron, desde una óptica participante, en los elementos políticos, ideológicos y organizativos del trabajo por sobre las experiencias de los trabajadores ${ }^{5}$. Un ejemplo claro de este modelo explicativo aplicado a los trabajadores portuarios, que se ajusta a la caracterización esbozada para el colectivo, lo encontramos en la obra de Diego Abad de Santillán (2005, p. 103-173)6 editada por primera vez en 1933. Sus explicaciones trasponen en términos generales, las interpretaciones aceptadas para el movimiento obrero europeo, evidenciando serias carencias de carácter historiográfico cuya influencia perduró en parte de la producción histórica de períodos posteriores?

Sobre la interpretación y utilización de la obra de los militantes historiadores, Nicolás Iñigo Carrera (2006, p. 274) en su balance sobre la historia de los trabajadores en la Argentina, rescata el aporte de este grupo por la profunda imbricación de los autores con su realidad y denuncia que ‘...] Sólo la mirada desde una corporación profesional de los historiadores explica el discurso actual que considera a esos historiadores simples fuentes de información, ignorando su condición de productores de conocimiento [...]'. Desde nuestro punto de vista, entendemos que el señalamiento de las limitaciones metodológicas de este colectivo de obras y de posteriores apropiaciones de este modo de historiar al movimiento obrero, desde la perspectiva del estado actual de la historia laboral, no supone necesariamente un reduccionismo del tipo denunciado por el autor, sino que por el contrario, desde este enfoque es posible revalorizar los textos a través de lecturas renovadas ${ }^{8}$.

\footnotetext{
${ }^{5}$ Sobre este modo de historiar al movimiento obrero en relación con la producción historiográfica brasileña -pero entendemos que la afirmación es aplicable también al contexto de producción argentino, por eso la traemos a colación- Silva (2003, p. 27-28) sostiene que: '[...] A lectura da história, baseada numa memoria fragmentária e seletiva de lutas com aura legendária, torna-se muitas vezes a lectura de identidade de um grupo, contituindo-se em motivo de orgullo, fonte de mobilizaçào e coesào coletivas. Entretanto, sob o manto da continuidade, escondem-se as diferentas que o historiador debe inventariar [...]'.

${ }^{6}$ En referencia a los obreros portuarios confróntese especialmente los capítulos 5, 6, 7y 8.

7 Sobre la continuidad de este enfoque cfr. Plácido Grela (1990).

${ }^{8}$ Un ejemplo de esto último lo constituye la siguiente interpretación de las memorias militantes propuesta por Gutiérrez y Lobato (1992, p. 28): '[...] Aunque cada uno de estos textos puede ir
} 
Dentro de este primer grupo, se incluyen también las primeras encuestas obreras confeccionadas por funcionarios delegados por el Poder Ejecutivo Nacional, que constituyen fuentes de análisis de gran riqueza, entre las que podemos citar al informe presentado en 1904 por Bialet Massé. El enviado gubernamental presenta de este modo a los/as obreros/as involucrados/as en la carga y descarga de buques y ferrocarriles en la Argentina de inicios del siglo XX:

\begin{abstract}
Se comprende en este ramo los obreros que llevan las cargas al costado de los buques (trabajo en tierra); los que reciben y acomodan en el buque (trabajo a bordo), y los que hacen las operaciones contrarias. Se llaman también cargadores estibadores los que en los ferrocarriles, en los galpones de depósito de los acopiadores de cereales y pasto en las estaciones terminales de embarcadero cargan, descargan y apilan las mercaderías. Las cargas más importantes del Interior son los cereales y las maderas; y las descargas, el carbón y las mercaderías generales. Como las bolsas suelen sufrir averías en las diversas manipulaciones y transportes que se hacen hasta quedar estibadas en las bodegas de los buques, ha un ramo anexo que sellama bolseros y costureros, generalmente niños o mujeres; y a veces se encargan del peso de las bolsas, y se les da a los que esto hacen el nombre de romaneros. Se ocupan en estos ramos en el Interior de la República no menos de treinta mil hombres, constituyendo un ramo de los más interesantes del trabajo (BIALET MASSE, 1985, p. 375376)
\end{abstract}

Bialet Massé ofrece también una descripción detallada de las precarias y brutales condiciones de trabajo de los estibadores portuarios a principios del siglo XX (BIALET MASSE, 1985, p. 378-379). Por su informe es posible conocer entre otras cosas, que el peso de las bolsas cargadas por los estibadores había ido en aumento al momento de sus observaciones. Con la intención de economizar el costo de los envases, llegaron a registrarse cargas de hasta ciento diez kilogramos por bolsa; mientras que el peso máximo aceptado por los sindicatos era de setenta kilogramos. Según Bialet Massé, un estibador en una jornada de ocho horas era capaz de estibar mil bolsas diarias, lo que considerando el peso máximo acordado, equivalía a cargar sobre los hombros 70.000 kilos en una jornada normal. El trabajo en las bodegas de las embarcaciones donde debía acomodarse la carga también era arduo y difícil debido a las altas temperaturas registradas en los períodos de mayor demanda de trabajo en los puertos, atendiendo a los tiempos de cosecha de los principales productos exportados;

acompañado del calificativo que lo adscribe a una ideología determinada (anarquista, comunista, peronista) y de la persistencia del afán justificatorio por parte de los autores, las obras permiten ver de qué modo definen las experiencias vividas los dirigentes o militantes gremiales. Aparecen en ellas los motivos (roles, representaciones, símbolos) de un discurso construido, expresamente, como un contradiscurso al de su oponente en la esfera laboral-gremial y frente a los que ejercen el poder $[. . .]^{\prime}$ 
y a la atmósfera viciada de vapor de agua y del polvillo de los cereales, azúcar y carbón, que causaban afecciones respiratorias, trastornos dérmicos y problemas en la visión.

III.

A partir de la segunda mitad del siglo XX se asiste a un cambio en la producción académica y los modernos estudios sobre el trabajo se convierten en parte de la vida intelectual a nivel internacional (FRENCH, 2000, p. 291) ${ }^{9}$. En la Argentina con posterioridad a 1955 también se produjo un cambio de enfoques y temas en la historia laboral que se plasmó sobre todo a partir de las décadas de 1960 y 1970. Estos cambios se relacionan dialécticamente con la realidad internacional y nacional contemporánea signada por el despliegue de luchas políticas y sociales tanto en el llamado Tercer Mundo como en las metrópolis occidentales y el desarrollo de movimientos de liberación nacional y social que promovieron posturas más radicalizadas en los sectores intelectuales (IÑIGO CARRERA, 2006, p. 274). El foco de interés se orientó inicialmente hacia la formación de la Argentina moderna y su desarrollo económico en vinculación con la caracterización de la inmigración masiva y los modos de incorporación política de la clase obrera desde una perspectiva eminentemente sociológica (GUTIÉRREZ; ROMERO, 1995, p. 199-200). La agenda historiográfica, dentro de los sectores marginales que se dedicaban a la historia laboral en el país, incorporó el tratamiento del proceso modernizador y su impacto en la sociedad; así como el estudio de la vinculación existente entre las organizaciones sindicales y el sistema político peronista.

Un excelente ejemplo de esta producción, que si bien trata sobre los trabajadores en términos globales - también hace referencia a los trabajadores portuarios en el contexto del fenómeno urbano moderno en las ciudades portuarias- lo hallamos en la obra de J osé Panettieri (1967). El texto propone una periodización que se inicia hacia 1870, con la definición de un modelo de país apoyado en la inmigración y la importación de capitales, hasta la crisis de la economía agro-exportadora en 1930. El autor propone un análisis estructural de los trabajadores dando cuenta a través de datos cuantitativos minuciosos del fenómeno urbano asociado con el crecimiento demográfico, las condiciones habitacionales y de sociabilidad, las escalas salariales y el costo de insumos básicos tanto en Buenos Aires como en el interior del país, las organizaciones obreras y su vinculación con el Estado, y el desarrollo de la clase media. Este enfoque estructural, que representó un aporte fundamental en su momento, puede enriquecerse a través de su articulación con perspectivas de análisis cultural que

${ }^{9}$ Versión digital en: http:/ fds.duke.edu/ db?attachment-2--1412-view-54 
posibiliten un conocimiento más amplio de la historia de los trabajadores. En este sentido, coincidimos con Suriano en que el diálogo entre procesos de trabajo, relaciones laborales y organizaciones, y las dimensiones culturales debería comprender temas tales como

el estudio de diferentes grupos de trabajadores, de diferentes ramas industriales, del pensamiento empresario, los sistemas de valores, las ideas de empresarios y trabajadores (varones y mujeres), la conformación de instituciones y de profesionales vinculados al mundo del trabajo, las relaciones entre el Estado y los trabajadores y los vínculos entre trabajadores y política (SURIANO, 2006, p. 305)

Desde mediados de la década de 1980 en adelante los cambios en el campo de la historia laboral latinoamericana y caribeña se han profundizado notablemente, aumentando la cantidad de estudios con nuevos y diversos enfoques, acercamientos multidisciplinares ${ }^{10}$, metodologías, temas, contextos nacionales y recortes temporales sobre temas vinculados mayoritariamente con la clase obrera y el trabajo urbano ${ }^{11}$. Asimismo, en la región se crearon instituciones que focalizaron recursos y energía intelectual en el desarrollo de investigaciones sobre los trabajadores urbanos y los movimientos populares, y se acentuó la proliferación de publicaciones periódicas sobre el tema. J ohn French (2000, p. 282-284) califica a este proceso como el boom de los estudios laborales latinoamericanos ubicándolo en el cuadro de situación descrito por Marcel van der Linden para Asia y el llamado Tercer Mundo en general $^{12}$. Según éste último, a nivel internacional tras el colapso del socialismo real, el campo de los estudios laborales se ha desarrollado de modo diferencial en las áreas centrales y las áreas periféricas manifestando una desincronía política y económica y

${ }^{10}$ Un ejemplo de este acercamiento interdisciplinario lo hallamos en el texto de Alberto Bialakowsky y Beatriz Fernández (1994) donde se resignifica el proceso de trabajo de estiba en el Puerto de Buenos Aires a partir de la identificación y el análisis de las relaciones sociales y del modo en que se articulan socialmente las asimetrías del poder en el puerto. El trabajo es definido por los autores por la dilucidación de tres elementos constitutivos: poder, extrañamiento y relación social; desde un enfoque cualitativo e interdisciplinario en el que termina imponiéndose una perspectiva sociológica que aúna el estudio de los elementos simbólicos y la materialidad del trabajo.

${ }^{11}$ French (2000, p. 280) sostiene que: "[...] Not unexpectedly, this shift in the locus of interest was linked to new perceptions of the political relevance of non-rural sectors of the region's popular classes: the visibility of urban workers in the Chilean revolution of Salvador Allende that was tragically aborted in the military coup of 1973; the courageous role that trade unions played in opposition to the dictatorships that ruled in Argentina, Brazil, Bolivia, Chile and Uruguay; and especially the spectacular rebirth of industrial militancy and political radicalism among the metalworkers of the ABC region of Greater Sào Paulo, Brazil between 1978-1980 [...]"

12 Según Marcel van der Linden (1999, p. 302) '[...] este declive, obvio en los países que han constituido tradicionalmente el "núcleo duro" del capitalismo, es sólo un fenómeno regional. No existe una "crisis" en sentido general de la sub-disciplina, a pesar de muchas afirmaciones sobre lo contrario. En el llamado Tercer Mundo, sobre todo en los países semi-periféricos en vías de industrialización, el interés por la historia del trabajo y la protesta proletaria está creciendo resueltamente. Este desarrollo desigual (una tendencia negativa en algunas partes del mundo y positiva en otras) revela una desincronía política y económica [...]' 
evidenciado la necesidad de repensar los ejes articuladores de la sub-disciplina tales como la conceptualización del nuevo proletariado y el concepto mismo de clase obrera.

A nivel nacional, esta renovación historiográfica impactó de modo diferencial y adquirió características propias que no responden exactamente a lo planteado por French para el contexto latinoamericano, puntualmente existe en la Argentina una valoración menos optimista del impulso transformador de dicha renovación en los años noventa. El cambio, en el contexto nacional, también se manifestó en la formulación de nuevos temas, enfoques y preguntas focalizadas en aspectos sociales y culturales ${ }^{13}$ por sobre las referentes a la organización sindical y las huelgas que articularon la literatura preexistente; posibilitando la conformación de una nueva historia de los trabajadores. Sobre este aspecto -la existencia de una renovación conceptual y metodológica en el campo historiográfico a partir de los años ochentaexiste un consenso generalizado en la historiografía nacional, no así en la caracterización del mismo ni en sus derivaciones posteriores ${ }^{14}$. Estas cuestiones exceden el enfoque de nuestro trabajo por lo que no nos adentraremos en su discusión, pero no queríamos dejar de explicitarlas.

Sobre lo que sí existe consenso para este período, es sobre la creciente influencia de la historia social en la historia laboral y sobre la influencia de los historiadores marxistas británicos, especialmente E.P. Thompson y Eric Hobsbawm, en los debates sobre la nueva agenda de temas de investigación en la Argentina. Su recepción a partir de los años 80 en los ámbitos profesionales, aunque tardía y dispar en relación a otros países latinoamericanos, supuso una renovación esencial en el descentramiento del problema del ámbito de trabajo, en la definición de sujetos de análisis más amplios y en la consideración de aspectos tales como las condiciones de la vida material en ámbitos micro-sociales de análisis.

Específicamente en cuanto a los trabajadores portuarios, Eric Hobsbawm (1979, p. 215-243) desarrolló en la década del 60 del siglo XX un modelo de análisis de los sindicatos nacionales en las zonas portuarias británicas para el período 1889-1914. Entendemos que el mismo, además de su interés intrínseco, puede resultar de gran utilidad para el establecimiento de ejes analíticos y temáticos que posibiliten la ubicación de nuestros sujetos de estudio en un marco comparativo más amplio y

13 Suriano (2006, p. 285) enumera los nuevos tópicos de interés profesional referidos: '[...] a la experiencia de la clase obrera, las condiciones de existencia material, la importancia del lugar de trabajo, el rol desempeñado por el Estado, la vida cotidiana, las comunidades, la etnicidad, las simbologías y las ritualidades [...]'.

${ }^{14} \mathrm{Al}$ respecto cfr. Gutiérrez y Romero (1995, p. 195-212), Gutiérrez y Lobato (1992, p. 25-49); Suriano (2006, p. 285-306); Iñigo Carrera (2006, p. 271-284) y Enrique Mases y Lisandro Gallucci (2007, p. 7-32) 
complejo. El autor propuso que para responder al interrogante sobre la forma que asumió la organización sindical en el espacio social considerado, era preciso tener en cuenta: la lógica de la posición de los trabajadores portuarios y los cambios históricos que alteraron el contexto de la negociación colectiva en los puertos. Según el historiador inglés, en las zonas portuarias era posible hallar representados todos los modelos alternativos de sindicalismo: el de oficios separado y local (Ej. Estibadores); el gremial compuesto (Ej. Marineros y carreteros); el general (operaba en distintos puertos) y el de industria local, regional o nacional. Esta situación obedecía a que las características mismas del trabajo en el puerto y sus fronteras fluidas, determinaron que no hubiera ningún grupo predestinado a convertirse en núcleo del sindicato, como sí sucedió en otras industrias. Por ello es preciso entonces investigar en cada contexto témporo-espacial en particular, qué forma asumió la organización obrera. Hobsbawm enumeraba a su vez, algunos de los problemas que se les presentaron a los organizadores sindicales en los muelles incluyendo entre ellos a: la delimitación de la entrada al oficio; la disímil valoración del trabajo eventual entre los distintos grupos de obreros y cómo evitar que los sectores fuertes constituyeran su propio gremio dejando a los débiles a merced del mercado, o en su defecto cómo lograr una coordinación efectiva entre los diversos sindicatos. Asimismo, planteaba las dificultades existentes para lograr unificar las demandas concretas de los obreros en un común denominador, en función del carácter eventual del trabajo y de las variaciones salariales. Por estos motivos señalaba que la unión se apoyaba en un primer momento casi exclusivamente en la solidaridad de clase frente a las reivindicaciones puntuales de cada huelga. Paralelamente, entre los factores que evitaron la dispersión y atomización de los trabajadores, evidenciando la necesidad de una acción colectiva común, el autor señalaba: 1. la homogeneización de los trabajadores ejercida desde la perspectiva del mundo externo al puerto, todos eran percibidos como peones eventuales ${ }^{15}$; 2 . la relativa debilidad de los obreros, aún de los especializados -cuyas calificaciones y experiencias no eran uniformes y se hallaban fuertemente localizadas- en el marco cada vez más

15 Según Hobsbawm (1979, p. 225-230) es erróneo caracterizar a la industria como si estuviese integrada exclusivamente por obreros eventuales y no calificados. Para el autor, la homogeneización de los trabajadores portuarios obedece más a la imposición de una perspectiva externa, donde todos eran percibidos como peones en teoría completamente eventuales; que a un análisis minucioso del mundo del trabajo en los puertos y cita como ejemplo el caso de los estibadores. Los cargadores especializados, los elevadores y quienes acomodaban la carga en las embarcaciones debían poseer fuerza, equilibrio, destreza, amplia experiencia, capacidad de decisión para realizar la carga y descarga de los diferentes tipos de barcos, así como la idoneidad para supervisar a otros trabajadores. Capacidades que los convertían en obreros cuasi irremplazables e inmunes a la contratación eventual, sobre todo en las bocas exportadoras donde el almacenamiento a bordo poseía mayor importancia. No obstante esto, el resto de los trabajos desarrollados requerían una calificación y fuerza más pequeña y presentaban en consecuencia un carácter auténticamente eventual y sujeto a las imposiciones de los contratistas e intermediarios. 
integrado del puerto moderno; y 3. la anulación progresiva de las distinciones entre obreros calificados y semicalificados ejercida por la mecanización del proceso de trabajo. Otros factores cohesionantes identificados son: la unificación operada entre los patronos del sector, las crisis económicas que llevaron a los portuarios a afrontar los mismos conflictos al mismo tiempo y la radicalización del movimiento obrero.

En cuanto a los factores que contribuyeron a la estabilización del mercado de trabajo, Hobsbawm identificaba a ciertos estímulos que coadyuvaron, junto con la mecanización, a la racionalización de las relaciones laborales en las zonas portuarias. Los mismos comprendían a la presión ejercida por la organización sindical, a la mediación estatal, al interés económico de los patrones por reorganizar el proceso productivo y a la regularización progresiva de la demanda de mano de obra.

Finalmente, como tendencia general de las zonas portuarias, el autor verificaba en su estudio del caso británico la tendencia a desarrollar 'sindicatos globales industriales y generales pero sobre todo nacionales, a pesar de su tendencia inherente hacia la autosuficiencia local y sectorial'16.

IV.

En este contexto de renovación historiográfica, presentado más arriba, se insertan también los aportes más significativos disponibles sobre la historia de los trabajadores portuarios en el país, entre los que destacamos la propuesta de Ricardo Falcón para el análisis del puerto de Rosario y la de Geoffroy de Laforcade sobre el puerto de Buenos Aires.

Ricardo Falcón ha señalado la importancia de los trabajadores portuarios en la etapa agro-exportadora en reiteradas oportunidades. Sin embargo, no ha tratado el tema de manera autónoma sino que ha inscripto su abordaje, focalizado en el puerto de Rosario, en distintas obras referidas a la evolución de los sectores populares urbanos durante la etapa inicial de la transformación capitalista en el país. Para el autor, el estudio de la temática desde la perspectiva del mundo del trabajo debe dar cuenta no solamente del mundo laboral sino también de las relaciones establecidas fuera de ese ámbito, indagando sobre el hábitat, las pautas de consumo y las cuestiones

\footnotetext{
${ }^{16}$ Sin embargo aclara que '[...] no hay que confundir la industria tal como efectivamente operaba desde el punto de vista de las relaciones laborales, con las industrias ideales construidas por los estrategas del movimiento obrero y del gobierno o por los economistas. Estos últimos pensaban desde el punto de vista del transporte o, a lo sumo, en el transporte por agua. La vida, en cambio, operaba desde el punto de vista de los puertos [...] Lo esencial es que, hasta ahora, una huelga portuaria sigue basándose fundamentalmente sobre la capacidad de perturbación de la economía por parte de los trabajadores de los muelles y de los que operan entre los muelles y los barcos o entre barco y barco, y no sobre la de los que llegan y salen por las entradas de los puertos'. (HOBSBAWM, 1979, p. 241-243)
} 
de salubridad en el escenario real de los trabajadores (FALCON, 2005, p. 10-13). En cuanto a éste último tema, en los puertos los accidentes de trabajo estaban a la orden del día. Según Falcón (1986, p. 25-26) la mayoría de ellos se debían a fallas materiales o a deficiencias en la organización del trabajo. Entre las causas más habituales el autor identifica: 1. la utilización de cargas de peso mayor a la que la resistencia de la pluma del guinche podía soportar; 2 . la deficiente distribución de las cargas: los trabajadores solían patinar al transitar la pasarela que unía el muelle con el barco porque ésta se encontraba muy inclinada debido al bajo nivel del agua o a que el barco se hallaba descargado; 3. el corriente quiebre de las tablas que actuaban como planchadas, cuyo mantenimiento era deficiente; 4 . los ritmos extremadamente acelerados de trabajo: en períodos de actividad pico se les ofrecía a los obreros primas por terminar el trabajo antes de lo previsto, lo que incrementaba la posibilidad de sufrir accidentes; y finalmente 5. durante los lapsos huelguísticos la impericia de los esquiroles también atentaba contra la seguridad en el trabajo.

En relación con el trabajo en el puerto de Rosario, pero entendemos que la hipótesis es válida también para el contexto nacional, Falcón sostiene que su estudio es sumamente relevante,

en primer lugar, por su condición estratégica en el mundo de las relaciones económicas y sociales de la ciudad nexo. En segundo lugar, porque es uno de los ejes de la cruzada disciplinadora del trabajo por parte de la elite. Y en tercero, porque los obreros portuarios fueron durante varios años un gremio líder en el seno del movimiento obrero (FALCON, 2005, p. 80)

La situación estratégica de las zonas portuarias, se vincula con la inserción del país en un contexto de modernización periférica que sobre determinó la relación capital/trabajo durante todo el período potenciando el desarrollo de los nodos exportadores/importadores. El término ciudad nexo alude al vínculo entre la producción agraria de la pampa húmeda y la exportación de ultramar y a la relación entre la mano de obra rural y urbana que se materializó en estos centros urbanos. En segundo lugar, la cruzada disciplinadora de la elite respondió, según el autor, a las particularidades de la organización social y técnica del trabajo en los muelles y barcos. Los sectores dominantes intensificaron la represión ejercida sobre los trabajadores al percibir su capacidad de alteración económica y social a través de las huelgas; y desarrollaron estrategias particulares de ejercicio de poder. Estrategias entre las que se inscribe, por ejemplo, la creación de la Unión Protectora del Trabajo Libre ${ }^{17}$ con el

17 Esta sociedad reunió a miembros de las empresas navieras, ferroviarias y comerciales vinculadas con tráfico agro-exportador en el puerto, con el propósito de contrarrestar de manera conjunta las 
objetivo de intervenir de manera conjunta frente a la conflictividad laboral desatada. Por último, la preponderancia del gremio de los obreros portuarios se relaciona con el lugar estratégico que ocuparon dentro de la economía agro-exportadora y a su capacidad para paralizar el flujo de mercancías. Entre los principales reclamos de los trabajadores el autor enumera la disputa por el peso de las bolsas, el rechazo a los intentos de reducción salarial, la aprobación de la jornada de ocho horas y la pugna por el control de los modos de contratación.

Otra cuestión vital señalada por Falcón (2005, p. 81) para el estudio de los portuarios, es la puja por el control del sistema de contratación, el reclutamiento de la mano de obra y el monopolio en el manejo de cuotas significativas de obreros ${ }^{18}$. En relación al tratamiento de este tema, Fernando Teixeira da Silva en su investigación sobre los trabajadores portuarios en la ciudad de Santos, Brasil, en los años transcurridos entre las dos guerras mundiales, propone una definición ampliada del concepto de control obrero ${ }^{19}$, que posibilita la articulación entre el proceso de trabajo y la organización de clase procurando un abordaje que aúne las nociones de cultura del trabajo y movimiento obrero. Entendemos que esta perspectiva de abordaje es sumamente interesante y que su aplicación, atendiendo a las especificidades del contexto histórico nacional, posibilitaría un acercamiento más profundo a la realidad de los trabajadores portuarios en la Argentina, operativizando la propuesta inicial de Falcón y posibilitando a su vez, el establecimiento de un criterio de análisis comparativo extra-nacional.

Otro tema de investigación formulado por Falcón (2005, p. 81) es el referido a la organización social y técnica del trabajo en el puerto, que evidencia la

consecuencias de las huelgas portuarias y generales acaecidas entre 1901 y 1905, en las que los estibadores desempeñaron un rol protagónico (FALCON, 2005, p. 82).

18 Sobre el tema Falcón (1986, p. 71) afirma que '[...] a principios de siglo el sindicato obrero del puerto de Buenos Aires había alcanzado a imponer que el $40 \%$ de los portuarios fueran elegidos entre sus miembros. Esta proporción se mantenía con alternativas según los altibajos de los movimientos huelguísticos [...]'

19 Silva (2003, p. 25-26) entiende al control obrero '[...] Em primeiro lugar, prende-se aos aspectos generalmente a ele dedicados pela literatura, ou seja, a luta dos trabalhadores no processo produtivo com a finalidade de obter ampla margen de comando da organizaçáo do trabalho. Tal luta implica a açào operária destinada a resistir a estratégias de controle empresarial dos locais de trabalho, consideradas arbitrárias, despóticas e contrárias á dignidade de operários que se identificavam como produtores de riquezas. Assim, a luta pelo controle de organizaçào do trabalho tornou-se o coraçào das açòes de amplas parcelas de classe operária. Além dos aspectos estritamente relacionados ao processo produtivo, o controle operário debe ser considerado de um ponto de vista mais amplo, estendendo-se á noçào de um controle de suas própias vidas. Trata-se de um conceito que abarca um conjunto de lutas multifacetadas e com variados fins, abarcando melhores condiçòes de vida e trabalho. Assim, engloba as lutas por segurança no emprego, disminuiçào da jornada de trabalho, aumento salariais e controle do mercado de trabalho [...] Essas açòes nào têm como objetivo apenas expresar a condiçào social dos trabalhadores, mas também obter reconhecimento público, exprimindo os limites de seu pertencimento e de sua exclusào no interior da sociedade [...]' 
coexistencia de dos elementos aparentemente contradictorios entre sí, a. por una parte, condiciones de trabajo precarias, asociadas con la práctica de tareas que requerían baja especialización, y la relativamente poca mecanización ${ }^{20}$, modificada parcialmente a principios del siglo XX por la introducción de métodos modernos de intensificación del ritmo productivo; y b. la búsqueda permanente por parte de los patrones de intensificar el ritmo productivo a través de una fuerte disciplina con el objetivo final de reducir el costo de la mano de obra, en el marco del predominio sectorial del trabajo eventual $^{21}$ y de los límites que esta situación inflingía a la mecanización y racionalización del trabajo. Según Falcón, este sistema era portador de una doble discriminación hacia los trabajadores: una de carácter étnico, ya que los capataces solían escoger a obreros de una nacionalidad en detrimento de los de otras, y otra político-ideológica, al discriminarse a los trabajadores sindicalizados en las sociedades de resistencia. De este modo Falcón introduce un tema importante dentro de la "nueva historia de los trabajadores", al que denomina la cuestión política y que incluye: la contienda entre movimientos y partidos, la existencia de una problemática étnica (gringos y criollos) y el proceso de formación de la clase obrera en Rosario, cruzando de este modo la cuestión social, la cuestión política y la cuestión étnica.

Con relación a este tema, más allá del importante aporte realizado por

Falcón en el estudio de caso del puerto de Rosario, compartimos el diagnóstico formulado por Suriano ${ }^{22}$ de la permanencia de ciertos interrogantes sobre la relación clase-etnicidad en la historia de los trabajadores argentinos, tales como:

\begin{abstract}
¿cómo influye el problema étnico en el proceso de formación de clases?, ¿qué papel jugaron las cuestiones referidas a la etnicidad en el proceso de integración del trabajador inmigrante en la nueva sociedad? Y más estrictamente, esas diferencias étnicas que dividían a la sociedad en general, ¿cómo se manifestaban en el lugar de trabajo no sólo en los momentos de emergencias de conflictos sino también en la experiencia laboral cotidiana? (SURIANO, 2006, p. 299)
\end{abstract}

20 Cabe señalar que recién en la década inicial del siglo XX aparecen las primeras cintas transportadoras eléctricas en el país. Tecnología que supuso una mayor tecnificación y simplificación del trabajo, reduciendo el esfuerzo personal y redundando en la disminución de la mano de obra requerida, con su correspondiente correlato de inquietudes y resistencias principalmente entre los estibadores (FALCON, 2005, p. 81)

21 En los puertos, el régimen de contratación vigente se organizaba a través de una red de intermediarios que seleccionaban diariamente a quienes trabajaban, de acuerdo al requerimiento estacionalmente variable de mano de obra. Según describe Agustina Prieto (2001, p. 138-139) los trabajadores se reunían al amanecer esperando ser seleccionados por los encargados de repartir las chapas de conchavo, quienes elegían a los obreros teniendo en cuenta tanto sus condiciones físicas, como su coincidencia ideológica o su afinidad étnica.

22 Suriano (2006, p. 298) sostiene que uno de los problemas centrales de la historiografía argentina en la década del ochenta y aún vigente '[...] era cómo resolver las tensiones entre una identidad étnica que se construía en el país receptor a expensas de las identidades regionales y una identidad de clase que a veces tendía a borrar esas diferencias a fuerza de vocear un internacionalismo proletario [...]' 
El segundo aporte sustantivo al estudio de los trabajadores portuarios en la Argentina de la primer mitad del siglo XX al que nos referiremos es la tesis doctoral de Geoffroy de Laforcade, Dockworkers, mariners, and the countours of class identity in the port of Buenos Aires, 1900-1950', defendida en la Universidad de Yale en 2001. Este trabajo, dirigido por Emilia Viotti da Costa, es la única obra referida específicamente a la temática que hemos hallado dentro de la producción de la historia social del trabajo; y decidimos introducirla con esta cantidad de datos porque entendemos que ellos nos informan también sobre los contextos actuales de circulación de la historia laboral a nivel continental.

Geoffroy de Laforcade reconstruye en su tesis el mundo del trabajo en el puerto de Buenos Aires atendiendo a la relación existente entre las ideologías vigentes (anarquismo, sindicalismo, comunismo, socialismo, conservadurismo, nacionalismo y populismo) y las experiencias cotidianas de los trabajadores, el proceso de trabajo y la acción colectiva en el área estudiada; intentando de este modo explicitar el proceso de formación de una identidad de clase específica. La identidad de clase, tema central del texto, es analizada en relación dialéctica con la reconstrucción de la experiencia de los trabajadores en un espacio relacional acotado, portador de una memoria social propia que determinó la existencia de ciertos vínculos laborales y comunitarios en el puerto y sus inmediaciones ${ }^{23}$. El mundo del trabajo en los muelles se reconstruye en el texto a través del estudio de las tradiciones organizacionales, los patrones de inmigración, las identidades urbanas y cívicas y las relaciones establecidas con el Estado; sumando de este modo interrogantes sobre la cultura barrial y la vida obrera a las clásicas preguntas sobre la sindicalización de los trabajadores.

En cuanto a la periodización elegida por de Laforcade (1900-1950), la misma supera la división tradicional entre la fase gestacional del movimiento obrero argentino y el peronismo como tópicos aislados de la historia laboral. El autor propone una visión de largo plazo que pretende, entre otras cosas, mostrar cómo los lenguajes del anarquismo y el peronismo reflejaron aspiraciones de clase compartidas (DE LAFORCADE, 2001, p. 13). En términos generales, los recortes temporales propuestos, si bien sus motivos no son explicitados en todos los casos, responden a los distintos

${ }^{23}$ Para de Laforcade (2001, p. 364) '[...] To understand occurrence of "class" is not just to placate a master narrative of group formation on diverse shades of subjectivity. It is to identify the relational spaces or settings within which social identities and representations take form, to locate the places and interpret the meanings of workers' agency in the conflictual context of their oppression, exclusion or marginalization from power. While not all resistance against alienation and fragmentation takes on the form of collective actions, "class" is an endeavor of symbolic unification and sedimentation over time, a hierarchization of events and organization of experience by the actors and institutions of organized labor [...] Seen in this light, "class" is invented by people, and its representation is storied by the social memory of their experience, their idioms, beliefs, prejudices, dreams and neuroses [...]' 
momentos por los que pasó la organización sindical en relación con los restantes agentes que conformaron el campo de lucha en el puerto de Buenos Aires.

Otras dos dimensiones de análisis consideradas en la tesis, asociadas con las propuestas renovadoras provenientes del cruce de la historia social y la laboral, son la etnicidad y la perspectiva de género. La cuestión étnica es abordada en conjunto con el proceso de formación de clase, como un proceso situacional de negociación de la identidad, más que como un simple indicador de la descendencia nacional de los trabajadores portuarios (DE LAFORCADE, 2001, p. 117). Por su parte, el género, en tanto herramienta analítica, es aplicado con el objeto de revelar los significados culturales de las distintas percepciones de las diferencias sexuales que subyacen a la división del trabajo, y el modo en que estas repercutieron en el discurso de identidad de clase. En tal sentido, de Laforcade (2001, p. 126) sostiene que

It was the culture of male sociability on the docks and ships, in the taverns, union and hiring halls, and the symbolic detachment of waterfront workers from the broader community, their spatial and social belonging to a distinct brotherhood of men with strong ties to places and institutional associated with organized labor and its history, that rendered the celebration of masculinity and male heroism so intrinsic to their public discourse

Por último, más allá del análisis de las propuestas puntuales de Eric Hobsbawm, Ricardo Falcón y Geoffroy de Laforcade sobre las que nos hemos extendido en función de los aportes específicos que cada una de ellas representa para el conocimiento de los trabajadores portuarios, nos interesa agregar algunas cuestiones sobre la situación de los estudios laborales en la Argentina a partir de la década del `90 del siglo XX. Las mismas se asocian con las transformaciones estructurales del sistema capitalista a nivel internacional que impactaron a nivel nacional y regional ${ }^{24}$. Según J uan Suriano (2006, p. 286-290) la crisis de la historia de los trabajadores se vincula con la crisis de la sociedad del trabajo, que implicó el desplazamiento de la centralidad de la clase obrera y sus instituciones, y al cambio de paradigmas historiográficos que privilegian los análisis políticos por sobre los económicos y sociales, instalando nuevas agendas de investigación en las que los trabajadores han sido relegados a lugares secundarios. Por su parte, Nicolás Iñigo Carrera (2006, p. 280-284) relaciona esta

24 Para Mases y Gallucci (2007, p. 8), ‘[...] resulta difícil sobrevalorar la importancia de los efectos que produjo la aplicación de las políticas económicas neoliberales durante la década de 1990, los cuales no se agotaron en el fenómeno de la exclusión social, sino que dejaron también su huella en el ámbito académico. En un contexto marcado por el incremento rampante del desempleo, el trabajo pareció perder el lugar central que - al menos desde la segunda posguerra- había ocupado en la experiencia vital de las personas al constituir la puerta de acceso al bienestar material y a los derechos de ciudadanía [...]' 
crisis de los estudios laborales con el predominio del empirismo y el eclecticismo, proponiendo en su lugar la recuperación del conocimiento acumulado y sistematizado en fuertes cuerpos teóricos. Sobre este último punto coincidimos con French (2002, p. 24-25) ${ }^{25}$ en que el enriquecimiento y expansión de la historia social en las últimas dos décadas, sobretodo en relación al género, el análisis discursivo y las subjetividades, representan posibilidades de apertura teórica y metodológica antes que amenazas para el desarrollo de la historia laboral en la actualidad. En este sentido entendemos que la revalorización de los estudios sobre los trabajadores en Latinoamérica debería asociarse con la redefinición de sus objetos de estudio, así como de los recortes témporo-espaciales tradicionales y la aplicación de nuevos marcos de análisis comparativos.

Como se observa la percepción de una crisis de los estudios sobre los trabajadores en la década del '90 del siglo XX es compartida en el campo historiográfico nacional, aunque no así su caracterización y evaluación. No es nuestra intención, como ya adelantamos, profundizar sobre esta cuestión pero si entendemos que es necesario mencionarla y tenerla presente porque sus implicaciones repercuten de manera directa en el modo en que se concibe el futuro de las investigaciones laborales y nuestra inserción/participación no sólo en los ámbitos profesionales sino también en el actual contexto histórico latinoamericano.

\section{A Modo de Conclusión: Algunas Cuestiones Pendientes}

Los puertos constituyen espacios de fronteras fluidas y poco nítidas que conjugan formas de trabajo viejas y nuevas y, en tanto categorías de análisis social, se hallan sujetos a disputas de sentido según la perspectiva con la que se los considere. En los puertos se llevan a cabo una multiplicidad de actividades que comprenden desde la carga y descarga de mercancías, el mantenimiento de las instalaciones de los muelles y las tareas burocráticas, hasta las tareas de control. En tal sentido, las experiencias de los trabajadores en los puertos pueden estudiarse situándolas específicamente en los barcos, en los muelles, en las dársenas, en los distintos complejos portuarios, en su vinculación con la comunidad de la cual forman parte, o en sus variadas vinculaciones con macro ámbitos de acción (regionales, nacionales y/ o internacionales). Los agentes involucrados en el mundo del trabajo portuario no presentan roles definidos a priori, sus posturas frente a los distintos temas y problemas se modificaron a lo largo del tiempo en función de su grado de cohesión/fragmentación interna, a su organización y/ o institucionalización y a su interacción con los restantes agentes. El reconocimiento

25 Versión digital en: http:/ fds.duke.edu/ db?attachment-2--1412-view-47 
de esta situación como punto de partida, pone de manifiesto la necesidad de repensar la temática con todas sus complejidades desde una perspectiva teórica y metodológica que de cuenta de la heterogeneidad intrínseca de los trabajadores portuarios en sus contextos de acción. Entendemos necesario establecer un diálogo abierto entre micro y macro ámbitos de análisis que posibilite la identificación de las especificidades propias de esta actividad en relación con los cambios coyunturales y estructurales del período histórico considerado.

La importancia de los trabajadores portuarios en la conformación del movimiento obrero nacional ha sido rescatada desde el inicio por los protagonistas de las primeras organizaciones obreras. Su relevancia se vincula con la centralidad que el trabajo adquirió en la configuración de la Argentina moderna como tema destacado de la agenda pública. Los rasgos distintivos del proceso de modernización periférica en el país y su impacto específico en las ciudades portuarias determinaron la constitución del mundo del trabajo en los puertos nacionales en el período en cuestión.

Los primeros enfoques sobre la temática se centraron en la presentación de los conflictos de clase, desde una óptica participante y auto justificatoria, focalizándose en la discusión de cuestiones político-ideológicas por sobre las experiencias de los trabajadores en sus lugares de trabajo y ámbitos comunitarios. Sus principales fuentes fueron los periódicos obreros, los congresos y las distintas declaraciones de las organizaciones obreras, además de la propia experiencia de sus autores. En términos generales, las explicaciones ensayadas en esta etapa inicial tendieron a interpretar los hechos y procesos locales según los modelos propuestos para el movimiento obrero europeo, desatendiendo las especificidades propias del contexto histórico nacional y latinoamericano.

Los enfoques posteriores se orientaron mayormente al estudio de la configuración de la Argentina moderna -atendiendo a sus características económicas estructurales-, de la influencia del proceso de inmigración masiva y de los modos de cooptación política de la clase obrera desde una perspectiva eminentemente sociológica. La investigación del proceso modernizador desde esta óptica posibilitó un conocimiento más acabado de las condiciones de existencia material de los trabajadores urbanos expresado en términos cuantitativos, sobre todo en relación al impacto demográfico de la inmigración masiva, sus condiciones habitacionales y sus escalas salariales en relación con la eclosión del sistema agro-exportador. No obstante, en términos generales en estos trabajos las dimensiones culturales de análisis fueron dejadas de lado. Recién en los últimos veinte años del siglo XX, tras la vuelta a la democracia, nuevos temas, enfoques y metodologías comenzaron a desarrollarse en la 
historia laboral argentina privilegiando aspectos sociales y culturales. Este cambio tuvo su correlato a nivel internacional y puede expresarse a grosso modo como consecuencia de la incorporación a la historia de los trabajadores de los aportes de la historia social, sobretodo a través de la recepción de la obra de los historiadores marxistas británicos y de la apropiación local de la historia desde abajo. En este contexto de producción se insertan las propuestas de abordaje del mundo del trabajo portuario en Rosario y Buenos Aires de Ricardo Falcón y Geoffroy de Laforcade, las cuales incorporan algunas de las nuevas dimensiones de análisis en el estudio del proceso de formación de la clase obrera en los espacios considerados.

El objetivo central de la elaboración de este racconto, que reconocemos fragmentario e incompleto, sobre la historia de los trabajadores portuarios en la Argentina es delinear una agenda preliminar de trabajo para futuras investigaciones sobre el tema. Por este motivo hemos intentado inscribir de manera genérica el tratamiento de la temática dentro de los distintos contextos de producción profesional e históricos, porque entendemos que sólo comprendiendo esta imbricación en el pasado podremos reflexionar sobre nuestra situación en el presente. En este sentido deseamos enumerar algunas cuestiones que creemos pueden profundizar y complejizar el conocimiento del pasado de los trabajadores portuarios en la etapa agroexportadora en la Argentina:

1. Es preciso ampliar y resignificar los marcos témporo-espaciales de análisis. Cuando nos referimos a la etapa agro-exportadora estamos partiendo de un recorte temporal consensuado profesionalmente que nos permite un entendimiento previo sobre qué momento deseamos estudiar, pero este balizamiento temporal debe se reproblematizado desde una perspectiva endógena a partir criterios de investigación explícitos (como por ejemplo: la identificación de los momentos clave en el proceso de organización sindical en las zonas portuarias, o la hilación temporal de los hechos recortados por la memoria colectiva como fundantes de una identidad propia). En cuanto a los marcos espaciales es necesario, por un lado investigar lo ocurrido fuera de los grandes centros urbanos del litoral pampeano ${ }^{26}$ y por otro articular ejes de análisis

26 Esta es una deuda denunciada hace más de veinte años por Gutiérrez y Romero (1995) que aún no ha sido saldada. 
que permitan superar los marcos interpretativos nacionales ${ }^{27} \mathrm{y}$ establecer un diálogo más fluido con la producción latinoamericana sobre la temática.

2. Partiendo de la profunda imbricación que se registra entre los puertos y sus zonas adyacentes y a la fuerte identificación territorial de sus trabajadores es necesario articular el estudio de las experiencias de los obreros portuarios en los ámbitos de trabajo y en sus comunidades de inserción.

3. La recuperación de la trayectoria de sus organizaciones sindicales y el análisis de sus conflictos de clase debe dar cuenta tanto de los vínculos y experiencias compartidos entre los trabajadores como de las relaciones que establecieron con los empresarios y el Estado.

4. La reconstrucción del proceso de constitución de una identidad propia de los trabajadores portuarios debe incorporar la dimensión analítica del género. Es preciso explicitar la división sexual del trabajo subyacente en las formas de sociabilidad predominantes en los contextos portuarios, así como las representaciones culturales que justificaron la exclusión de las mujeres de los espacios de toma de decisión en las organizaciones obreras, a pesar de que su trabajo al igual que el de los niños ya había sido reconocido y expuesto desde principios del siglo XX en el informe de Bialet Massé.

5. Finalmente, creemos que la cuestión étnica en las zonas portuarias debe abordarse en el marco del estudio del proceso de formación clase atendiendo al modo específico en que se manifestó en los espacios de trabajo (por ej. en relación al acceso al empleo o a la adquisición de determinados oficios) y en las comunidades portuarias en vinculación con el establecimiento de espacios de sociabilidad diferenciados. Este tema debe además, asociarse con el estudio del significado de la ciudadanía para los trabajadores durante la etapa seleccionada (SURIANO, 2006, p. 290).

27 Un ejemplo de este tipo de iniciativas interpretativas en relación a los trabajadores vinculados a la exportación durante esta etapa en Latinoamérica lo hallamos en la obra de Charles Bergquist (1993, p. 757-764) 


\section{Referencia}

ABAD DE SANTILLÁN, Diego. La FORA: ideología y trayectoria del movimiento obrero revolucionario en la Argentina. Buenos Aires: Libros de Amarres, 2005.

HOBSBAWM, Eric. Los sindicatos en las zonas portuarias. In: __ . Trabajadores: Estudios de historia de la clase obrera. Barcelona: Editorial Crítica, 1979. p. 215-243.

BERGQUIST, Charles. Labor History and its challenges: confessions of a latin americanist. American Historical Review, Washington, v. 98, n. 3, p. 757-764, J un. 1993.

BIALAKOWSKY, Alberto; FERNÁNDEZ, Beatriz. Las articulaciones laborales: los estibadores del puerto de Buenos Aires. Buenos Aires: CEAL, 1994.

BIALET MASSE, J uan. Informe sobre el estado de la clase obrera. Madrid: Hyspamerica, 1985. t.1.

DE LAFORCADE, Geoffroy. Dockworkers, Mariners and the Contours of Class Identity in the Port of Buenos Aires, 1900-1950. 2001. Tesis (Doctoral) - Yale University, UMI Number 3007331.

FALCÓN, Ricardo. El mundo del trabajo urbano (1890-1914). Buenos Aires: Centro Editor de América Latina, 1986.

FALCÓN, Ricardo. La Barcelona argentina: migrantes obreros y militantes en Rosario 1870-1942. Rosario: Laborde Editor, 2005.

FALCÓN, Ricardo. Los orígenes del movimiento obrero (1857-1899). Buenos Aires: Centro Editor de América Latina, 1984.

FRENCH, J ohn D. A história latino-americana do trabalho hoje: uma reflexâo autocrítica. História-Unisinos, Sao Leopoldo, v. 6, n. 6, p. 11-28, 2002. Disponivel em: $<$ <ttp:/ fds.duke.edu/ db?attachment-2--1412-view-47>. Acesso em: 11 set. 2001.

FRENCH, J ohn D. The latin american labor studies boom. Internacional Review of Social History, Assen, v. 45, p. 279-308, 2000. Disponible em:<http:/ fds.duke.edu/ db?attachment-2--1412-view-54>. Acesso em: 11 set. 2001.

GRELA, Plácido. El estibador portuario: orígenes de la cooperativa y del sindicato de trabajos portuarios de Puerto General San Martín. Rosario: Ed. El Remanso, 1990.

GUTIÉRREZ, Leandro; LOBATO, Mirta. Memorias militantes: un lugar y un pasado para los trabajadores argentinos. Entrepasados, Buenos Aires, ano 2, n. 3, p. 25-49, 1992.

GUTIÉRREZ, Leandro; ROMERO, Luís Alberto. Los sectores populares y el movimiento obrero: un balance historiográfico. In: _.___. . Sectores populares, cultura y política: Buenos Aires en la entreguerra. Buenos Aires: Sudamericana, 1995. p. 195-212.

IÑIGO CARRERA, Nicolás. La historia de los trabajadores. In: GELMAN, J orge. La historia económica argentina en la encrucijada: balances y perspectivas. Buenos Aires: Prometeo Libros, 2006. p. 271-284. 
MASES, Enrique; GALLUCCI, Lisandro. La historiografía sobre los trabajdores en la Patagonia: un estudio preliminar. In: la Patagonia. Neuquén: Educo, 2007. p. 7-32.

PANETTIERI, J osé. La Crisis de 1873. Buenos Aires: CEAL, 1967.

PRIETO, Agustina. Los trabajadores. In: FALCÓN, Ricardo; STANLEY, Myriam. La historia de Rosario. Rosario: Homo Sapiens Ediciones, 2001. p. 111-155.

SURIANO, Juan. Los dilemas actuales de la historia de los trabajadores. In: GELMAN, J orge. La historia económica argentina en la encrucijada: balances y perspectivas. Buenos Aires: Prometeo Libros, 2006. p. 285-306.

SILVA, Fernando Teixeira da. Operários sem patróes: os trabalhadores de cidade de Santos no entreguerras. São Paulo: UNICAMP, 2003.

VAN DER LINDEN, Marcel. El fin del eurocentrismo y el futuro de la historia del trabajo; o por qué debemos y podemos reconceptualizar la clase obrera. In: PANIAGUA, J .; PIQUERAS, J. A.; SANZ, V. (Coord.). Cultura social y política en el mundo del trabajo. Madrid: UNED, 1999. p. 301-322.

Colaboração recebida em 02/ 03/ 2010 e aprovada em 15/ 08/2010. 